\title{
One Year of Dapaglifozin Add-On Therapy Ameliorates Surrogate Indexes of Insulin Resistance and Adiposity in Patients with Type 2 Diabetes Mellitus
}

Stefano Radellini - Enrica Vigneri • Valentina Guarnotta •

Felicia Panto · Carla Giordano (D)

Received: February 7, 2021 / Accepted: March 27, 2021

(C) The Author(s) 2021, corrected publication [2021]

\section{ABSTRACT}

Introduction: This study investigates the effects of dapagliflozin on the visceral adiposity index (VAI), lipid accumulation product (LAP), product of triglycerides and glucose (TyG) and triglycerides to HDL-cholesterol ratio (TG/HDLC) in patients with type 2 diabetes mellitus (T2D).

Methods: In this real-life study, dapaglifozin was added to metformin alone (group 1, no. 42) or insulin plus metformin (group 2, no. 58 ) in 100 T2D patients.

Results: In group 1, after 6 months of dapaglifozin addition, a significant decrease in BMI $(p<0.001)$, waist circumference (WC) $(p<0.001)$, systolic blood pressure (SBP) $(p=0.009)$, diastolic blood pressure (DBP)

Stefano Radellini, Enrica Vigneri and Valentina Guarnotta equally contributed to this work.

S. Radellini · E. Vigneri - V. Guarnotta $(\bowtie)$.

F. Panto - C. Giordano $(\bowtie)$

Section of Endocrinology, Department of Health Promotion Sciences, Maternal-Infant Care, Internal Medicine and Specialties of Excellence "G.

D'Alessandro" (PROMISE), University Hospital P.

Giaccone, University of Palermo, Piazza Delle

Cliniche 2, 90127 Palermo, Italy

e-mail: valentina.guarnotta@unipa.it

C. Giordano

e-mail: carla.giordano@unipa.it
( $p=0.012$ ), mean fasting blood glucose (FBG), post-breakfast glucose (PBG), post-lunch glucose (PLG) and post-dinner glucose (PDG) (all $p<0.001)$, HbA1c $(p<0.001)$, VAI $(p=0.020)$, LAP $(p=0.028)$, Tyg $(p<0.001)$, TG/HDL-C $(p=0.020)$ and glutamate pyruvate transaminase (GPT) $(p<0.001)$ was observed compared to baseline. After 12 months a significant decrease in BMI $(p<0.001)$, WC $(p=0.006)$, SBP $(p=0.023)$, DBP $(p=0.005)$, mean FPG, PBG, PLG and PDG (all $p<0.001$ ), HbA1c $(p<0.001)$, total cholesterol $(p=0.038)$, triglycerides $(p=0.026)$, VAI $(p=0.013)$, GPT $(p<0.001)$, LAP index $(p=0.024)$, Tyg index $(p<0.001)$ and TG/HDL-c ratio $(p=0.016)$ was observed compared to baseline. In group 2 , after 6 months of dapaglifozin addition, a significant decrease in BMI $(p<0.001)$, WC $(p<0.001)$, $\operatorname{SBP}(p=0.015), \operatorname{DBP}(p=0.007)$, mean FPG, PBG, PLG and PDG (all $p<0.001$ ), HbA1c $(p<0.001)$, VAI $(p=0.040)$, LAP $(p=0.047)$, Tyg $(p<0.001)$, TG/HDL-C $(p=0.048)$ and GPT $(p<0.001)$ was observed compared to baseline. By contrast, after 12 months a significant decrease in BMI $(p<0.001)$, WC $(p<0.001)$, SBP $(p=0.001)$, DBP $(p=0.002)$, mean FPG, PBG, PLG and PDG (all $p<0.001$ ), HbA1c $(p<0.001)$, GPT $(p<0.001)$ and Tyg index $(p=0.003)$ was observed compared to baseline. Conclusions: Dapagliflozin treatment significantly reduced surrogate indexes of insulin resistance and adiposity in patients with T2D. 
Keywords: LAP; Dapagliflozin; Visceral adiposity index; Cardiometabolic risk; Tyg

\section{Key Summary Points}

Sodium-glucose co-transporter type 2 inhibitors (SGLT2i) significantly improve cardiovascular and renal outcomes in patients with type 2 diabetes mellitus (T2DM)

This study aims to investigate the effects of dapagliflozin added to metformin in monotherapy or metformin plus insulin on the metabolic parameters, visceral adiposity index (VAI), lipid accumulation product (LAP), product of triglycerides and glucose (TyG) and triglycerides to HDL-cholesterol ratio (TG/HDL-C)in 100 patients with T2DM

The study confirms the efficacy of dapagliflozin in achieving stable metabolic and glycaemic control and contributing to the improvement in other extraglycaemic targets (BMI, WC, SBP, DBP and TG levels) in a real-life single-centre cohort of patients with T2DM

The study shows that dapaglifozin added to metformin or metformin plus insulin significantly improves surrogate indexes of insulin resistance and adiposity in patients with T2DM

The limitation of the study is the lack of a meaningful control group

\section{DIGITAL FEATURES}

This article is published with digital features, including a summary slide, to facilitate understanding of the article. To view digital features for this article go to https://doi.org/10.6084/ m9.figshare.14316128.

\section{INTRODUCTION}

Many novel antidiabetic therapies are available for the treatment of type 2 diabetes (T2D) [1] and have a good impact on glycaemic control but also on the distribution of adipose tissue, weight gain and chronic low grade inflammation [2]. Sodium-glucose co-transporter-2 inhibitors (SGLT2i) are novel oral hypoglycaemic drugs that produce glycosuria by blocking the reabsorption of glucose in the renal proximal tubules [3]. As a result, they improve glucose control through direct and indirect mechanisms, with limited risk of hypoglycaemia, and exert other positive effects on body weight, blood pressure, blood uric acid levels and inflammation [4]. In addition, the administration of SGLT-2i decreases abdominal visceral adipose deposits and improves their function [5-9]. Several studies have shown that when added to standard care, SGLT2i reduce the incidence of major cardiovascular events (cardiovascular mortality, non-fatal myocardial infarction, non-fatal stroke) in patients with T2D who are at high cardiovascular risk [10-12]. SGLT2i reduce the risk of hospitalization for heart failure and progression to end-stage renal disease in patients with T2D who have high cardiovascular risk, independent from glucose control [13].

The Visceral Adiposity Index (VAI) is an indirect validated gender-specific index, currently one of the best indicators of cardiovascular disease, which positively correlates with visceral adipose distribution and function [14] and adipocytokine levels, and it represents a surrogate index of cardiometabolic risk [15-17]. It can express both the altered endocrine function of adipose tissue and the state of relative leptin resistance and low-grade inflammation, which are all alterations of adipose tissue function. The gold standard to directly measure insulin sensitivity is the euglycaemic hyperinsulinemic clamp [18]. However, many surrogate indexes on insulin sensitivity have been modelled based on clinical and laboratoristic parameters including the lipid accumulation product (LAP), product of triglycerides and glucose (TyG) and the triglycerides to HDL- 
cholesterol ratio (TG/HDL-C) [19]. Therefore, to confirm the role of SGLT2i in determining an improvement of surrogate indexes of insulin resistance and adiposity in patients with $\mathrm{T} 2 \mathrm{D}$, in the current study we aimed to investigate whether dapaglifozin is able to influence the Visceral Adiposity Index (VAI), LAP, Tyg and TG/ HDL-C ratio indexes before and after 6 and 12 months of dapagliflozin treatment in a reallife cohort of outpatients with T2D.

\section{METHODS}

In this real-life study, we evaluated 100 outpatients of white race with T2D (57 men and 43 women; age range, 30-77 years), inadequately controlled with metformin alone (group 1, 42 patients; dual combined treatment; mean metformin dose $2428 \pm 367.6 \mathrm{mg}$ ) or metformin combined with insulin (group 2, 58 patients; triple combined treatment; mean metformin dose $2297 \pm 497.7 \mathrm{mg}$ ), who were started on dapagliflozin $10 \mathrm{mg}$ once daily as add-on therapy. Among patients treated with metformin and insulin, 20 were on basal-bolus insulin treatment, while 38 were on long-acting insulin treatment. Patients were followed up for 12 months in a real-world setting. Inclusion criteria were a previous diagnosis of T2D for at least 5 years, HbA1c $6.5-11 \%$ (48-$97 \mathrm{mmol} / \mathrm{mol}$ ), age ranging from 30 to 80 years, $\mathrm{BMI}<40 \mathrm{~kg} / \mathrm{m}^{2}$ and stable treatment with metformin alone or metformin and insulin of at least 3 years. We excluded patients with any other concomitant diabetes medications, moderate kidney disease (creatinine clearance $<60 \mathrm{ml} / \mathrm{min}$ using the Chronic Kidney Disease Epidemiology Collaboration [CKD-EPI] formula), high liver enzyme levels such as glutamate pyruvate transaminase (GPT) or glutamate oxaloacetate transaminase (GOT) more than three times above the upper limit of normal or total bilirubin $>2.0 \mathrm{mg} / \mathrm{dl}$, unstable blood pressure and coronary syndrome, symptomatic heart failure or alcohol abuse. Microvascular complications were evaluated as recommended by standard medical care of diabetes [20]. Diabetic retinopathy was evaluated by a comprehensive dilated eye examination with fundus photography by an expert ophthalmologist. Diabetic nephropathy was assessed by urinary albumin (e.g., spot urinary albumin-to-creatinine ratio) and the estimated glomerular filtration rate (GFR). Normal UACR was defined as $<30 \mathrm{mg} / \mathrm{g}$ creatinine and high urinary albumin excretion as $\geq 30 \mathrm{mg} / \mathrm{g}$ creatinine. GFR was calculated from serum creatinine using the CKD-EPI formula. Chronic kidney disease (CKD) was defined as stages $1-2$ by evidence of high albuminuria with eGFR $\geq 60 \mathrm{ml} /$ $\min / 1.73 \mathrm{~m}^{2}$, while stages $3-5$ were defined for lower ranges of GFR. Assessment for distal symmetric polyneuropathy was done by either temperature or pinprick sensation (small fibre function) and vibration sensation using a $128-\mathrm{Hz}$ tuning fork (for large-fibre function). Patients had also 10-g monofilament.

Lipid-lowering drugs were continued during the study. In the dual combined group, 36 out of 42 patients were on statin treatment, while in the triple combined group, 49 out of 58 patients were on lipid-lowering treatment. None was treated with TG lowering drugs.

In all patients, anthropometric and clinical parameters were evaluated at the baseline assessment and after 6 and 12 months of therapy, including BMI, waist circumference (WC), systolic blood pressure (SBP) and diastolic blood pressure (DBP). We also evaluated metabolic and biochemical parameters, self-monitoring blood glucose (SMBG) including mean fasting plasma glucose (FPG) and $2 \mathrm{~h}$ post-breakfast, post-lunch and post-dinner glycaemia (PBG, PLG and PDG) by glucometer, HbA1c, fasting total cholesterol, HDL-cholesterol and TG. The VAI was calculated as already described [15] using the gender-specific formulas:

- Male VAI $=[\mathrm{WC} /(39.68+(1.88 \times \mathrm{BMI}))] \times$ $(\mathrm{TG} / 1.03) \times(1.31 / \mathrm{HDL})$

- Female VAI $=[\mathrm{WC} /(36.58+(1.89 \times \mathrm{BMI}))]$ $\times(\mathrm{TG} / 0.81) \times(1.52 / \mathrm{HDL})$

Additional surrogate indexes of insulin sensitivity and adipose tissue function including the LAP index, TyG index, and TG/HDL-C ratio, which were found to be associated with subclinical vascular damage [19], were also calculated. The LAP index was calculated as $(\mathrm{WC}-65) \times(\mathrm{TGs}[\mathrm{mmol} / \mathrm{l}])$ in men, and 
$(\mathrm{WC}-58) \times(\mathrm{TG}[\mathrm{mmol} / \mathrm{l}])$ in women [21]. The TyG index was calculated as the $\operatorname{Ln}[$ fasting TGs $(\mathrm{mg} / \mathrm{dl}) \times$ fasting glucose $(\mathrm{mg} / \mathrm{dl}) / 2$ ] [22] The TG/HDL-C ratio was calculated as the ratio of TG $(\mathrm{mg} / \mathrm{dl})$ to HDL-C $(\mathrm{mg} / \mathrm{dl})$ [23].

The change from 12 months to baseline $(\Delta)$ for the parameters which were statistically significant changed after 6 months of dapaglifozin addition were calculated in both groups of patients. During the 12 months of follow-up, any change in concomitant medications was considered an exclusion criterion.

All procedures were in accordance with the ethical standards of the local committee on human experimentation (institutional and national) and with the Declaration of Helsinki (1964) and its later amendments. Approval was obtained from the Ethics Committee of the Policlinico Paolo Giaccone Hospital, University of Palermo (Ref. 04/2020). At the time of the first visit in our Out-Patient Clinic, all patients provided informed consent to participate in the study and for the publication of the study.

\section{Statistical Analysis}

SPSS version 19 (SPSS, Inc., Chicago, IL, USA) was used for data analysis. Data were presented as mean \pm SD or rates and proportions. The normality of distribution of the quantitative variables was assessed using the KolmogorovSmirnov test. The differences between the two groups were evaluated with Student's $t$-test for quantitative variables and $\chi 2$ for trend for categorical variables. Changes in parameters from baseline to 6 months and from 6 to 12 months were evaluated using the paired $t$-test. $p<0.05$ was considered statistically significant.

\section{RESULTS}

Baseline characteristics and comorbidities of both treatment groups are shown in Table 1. There were no significant differences between groups with regard to sex distribution, age, prevalence of arterial hypertension, cardiovascular disease, ischaemic stroke, peripheral artery disease, diabetic nephropathy and chronic kidney disease, while patients on dual combined treatment (metformin + dapaglifozin) had lower prevalence of diabetic retinopathy $(p=0.010)$, shorter duration of diabetes $(p=0.001)$, and lower HbA1c $(p=0.006)$, BMI $(p=0.015)$ and WC $(p=0.004)$ than triple combined treatment (metformin + dapaglifozin + insulin). None discontinued the treatment during the 12-month follow-up.

The anthropometric, metabolic and clinical parameters before and after 6 and 12 months of dapaglifozin add-on metformin treatment alone (dual combined treatment) are shown in Table 2. After 6 months of dapaglifozin addition a significant decrease in BMI $(p<0.001)$, WC $(p<0.001)$, SBP $(p=0.009)$, DBP $(p=0.012)$, mean FPG, PBG, PLG and PDG (all $p<0.001$ ), HbA1c $(p<0.001)$, VAI $(p=0.020)$ and GPT $(p<0.001)$ was observed compared to baseline (Table 2). No significant differences were found from 12 to 6 months (Table 2). By contrast, after 12 months a significant decrease in BMI $(p<0.001)$, WC $(p=0.006)$, SBP $(p=0.023)$, DBP $(p=0.005)$, mean FPG, PBG, PLG and PDG (all $p<0.001)$, HbA1c $(p<0.001)$, total cholesterol $\quad(p=0.038), \quad$ TG $\quad(p=0.026), \quad$ VAI $(p=0.013), \quad$ GPT $\quad(p<0.001), \quad$ LAP index $(p=0.024)$, Tyg index $(p<0.001)$ and TG/HDLc ratio $(p=0.016)$ was observed compared to baseline (Table 2).

In the triple combined regimen group, a significant decrease in BMI $(p<0.001)$, WC $(p<0.001)$, SBP $(p=0.015)$, DBP $(p=0.007)$, mean FPG, PBG, PLG and PDG (all $p<0.001$ ), HbA1c $(p<0.001)$, VAI $(p=0.040)$, LAP index $(p=0.047)$, Tyg $(p<0.001)$, TG/HDL-C ratio $(p=0.048)$ and GPT $(p<0.001)$ was observed after 6 months of dapaglifozin addition compared to baseline (Table 3). No differences were found comparing 12 and 6 months (Table 3). By contrast, after 12 months a significant decrease in BMI $(p<0.001)$, WC $(p<0.001), \quad$ SBP $(p=0.001)$, DBP $(p=0.002)$, mean FPG, PBG, PLG and PDG (all $p<0.001)$, HbA1c $(p<0.001)$, GPT $(p<0.001)$ and Tyg index $(p=0.003)$ was observed compared to baseline (Table 3).

No differences between dual and triple combined regimens were observed in $\Delta \_$BMI, $\Delta \_$WC,$\Delta \_$SBP,$\Delta \_$DBP $, \Delta \_F B G, \Delta \_$PBG,$\Delta \_$PLG, $\Delta \_$PDG,$\quad \Delta \_$HbA1c, $\quad \Delta \_$GOT,$\quad \Delta_{-}$GPT,$\quad \Delta_{-}$VAI, 
Table 1 Clinical characteristics and comorbidities of patients with type 2 diabetes mellitus before starting dapaglifozin as added dual or triple therapy

\begin{tabular}{|c|c|c|c|}
\hline & $\begin{array}{l}\text { Dual combined therapy } \\
N=42 \\
\text { Subjects (\%) }\end{array}$ & $\begin{array}{l}\text { Triple combined therapy } \\
N=58 \\
\text { Subjects (\%) }\end{array}$ & $p$ \\
\hline \multicolumn{4}{|l|}{ Gender } \\
\hline Male & $24(57.1 \%)$ & $33(56.9 \%)$ & 0.660 \\
\hline Female & $18(42.9 \%)$ & $25(43.1 \%)$ & \\
\hline Smoking & $13(31 \%)$ & $28(48.3 \%)$ & 0.336 \\
\hline Cardiovascular disease & $3(7.1 \%)$ & $6(10.3 \%)$ & 0.972 \\
\hline Ischaemic stroke & 0 & $1(1.7 \%)$ & 0.256 \\
\hline Peripheral arterial disease & $2(4.8 \%)$ & $5(8.6 \%)$ & 0.393 \\
\hline Arterial hypertension & $29(69 \%)$ & $45(77.6 \%)$ & 0.477 \\
\hline Diabetic retinopathy & $4(9.5 \%)$ & $17(29.3 \%)$ & 0.010 \\
\hline Chronic kidney disease & $1(2.4 \%)$ & 0 & 0.373 \\
\hline Diabetic nephropathy & $3(7.1 \%)$ & $8(13.8 \%)$ & 0.236 \\
\hline \multirow[t]{2}{*}{ Diabetic neuropathy } & $3(7.1 \%)$ & $5(8.6 \%)$ & 0.587 \\
\hline & Mean \pm SD & Mean \pm SD & $p$ \\
\hline Age (years) & $57.6 \pm 8.21$ & $60.5 \pm 8.31$ & 0.089 \\
\hline Duration of diabetes (years) & $8.24 \pm 5.54$ & $14.1 \pm 9.94$ & 0.001 \\
\hline Body mass index $\left(\mathrm{kg} / \mathrm{m}^{2}\right)$ & $30.4 \pm 6.31$ & $33.3 \pm 4.93$ & 0.015 \\
\hline Waist circumference $(\mathrm{cm})$ & $105.7 \pm 12.9$ & $113.3 \pm 12.6$ & 0.004 \\
\hline HbAlc (\%) & $8.68 \pm 1.49$ & $9.48 \pm 1.23$ & 0.006 \\
\hline VAI & $3.04 \pm 1.87$ & $2.95 \pm 2.09$ & 0.812 \\
\hline LAP index & $86.1 \pm 52.4$ & $93.8 \pm 62.8$ & 0.505 \\
\hline Tyg index & $9.57 \pm 0.62$ & $9.57 \pm 0.61$ & 0.966 \\
\hline TG/HDL-C ratio & $4.12 \pm 2.54$ & $3.97 \pm 2.81$ & 0.789 \\
\hline
\end{tabular}

$V A I$ Visceral Adiposity Index, $L A P$ lipid accumulation product, $T y g$ product of triglycerides and glucose, $T G / H D L-C$ triglycerides to HDL-cholesterol ratio

$\Delta \_$LAP, $\quad \Delta \_$Tyg, $\Delta_{-}$TG/HDL-C, $\Delta_{-}$total cholesterol, $\Delta \_$HDL-cholesterol, $\Delta \_$TG and $\Delta_{-}$LDL-Cholesterol (Fig. 1).

Dapagliflozin was well tolerated, without differences in the occurrence of infections between the groups (data not shown).

\section{DISCUSSION}

In the current study, dapagliflozin as add-on therapy to metformin alone or metformin combined to insulin improved glycaemic control in patients with $\mathrm{T} 2 \mathrm{D}$ and led to a significant reduction in BMI, WC, SBP, the DBP LAP index, 
Table 2 Clinical, anthropometric and metabolic parameters in diabetic patients before and after dual combined therapy of dapaglifozin and metformin

Dual combined treatment (dapaglifozin + metformin)

\begin{tabular}{|c|c|c|c|c|c|c|}
\hline & $\begin{array}{l}\text { Baseline } \\
\text { Mean } \pm \text { SD }\end{array}$ & $\begin{array}{l}6 \text { months } \\
\text { Mean } \pm \text { SD }\end{array}$ & $\begin{array}{l}12 \text { months } \\
\text { Mean } \pm \text { SD }\end{array}$ & $p^{*}$ & $p^{* *}$ & $p^{* * *}$ \\
\hline Body mass index $\left(\mathrm{kg} / \mathrm{m}^{2}\right)$ & $30.4 \pm 6.31$ & $29.7 \pm 6.29$ & $29.4 \pm 6.32$ & $<0.001$ & 0.312 & $<0.001$ \\
\hline Waist circumference $(\mathrm{cm})$ & $105.7 \pm 12.9$ & $104.2 \pm 12.4$ & $104.1 \pm 12.2$ & $<0.001$ & 0.884 & 0.006 \\
\hline Systolic blood pressure $(\mathrm{mmHg})$ & $126.4 \pm 9.61$ & $123.2 \pm 6.46$ & $122.8 \pm 10.1$ & 0.009 & 0.723 & 0.023 \\
\hline Diastolic blood pressure $(\mathrm{mmHg})$ & $83.1 \pm 11.8$ & $79.3 \pm 9.46$ & $77.5 \pm 7.96$ & 0.012 & 0.179 & 0.005 \\
\hline Mean fasting glycaemia $(\mathrm{mmol} / \mathrm{l})$ & $11.1 \pm 2.66$ & $7.91 \pm 2.24$ & $8.12 \pm 3.62$ & $<0.001$ & 0.672 & $<0.001$ \\
\hline Mean $2 \mathrm{~h}$ post-breakfast glycaemia $(\mathrm{mmol} / \mathrm{l})$ & $11.3 \pm 2.21$ & $7.64 \pm 2.16$ & $8.57 \pm 3.54$ & $<0.001$ & 0.071 & $<0.001$ \\
\hline Mean $2 \mathrm{~h}$ post-lunch glycaemia $(\mathrm{mmol} / \mathrm{l})$ & $11.1 \pm 2.58$ & $8.29 \pm 2.41$ & $8.63 \pm 3.28$ & $<0.001$ & 0.381 & $<0.001$ \\
\hline Mean $2 \mathrm{~h}$ post-dinner glycaemia $(\mathrm{mmol} / \mathrm{l})$ & $11.6 \pm 2.66$ & $8.35 \pm 2.49$ & $8.2 \pm 3.04$ & $<0.001$ & 0.695 & $<0.001$ \\
\hline HbAlc (\%) & $8.68 \pm 1.49$ & $7.31 \pm 0.85$ & $7.53 \pm 1.41$ & $<0.001$ & 0.124 & $<0.001$ \\
\hline Total cholesterol $(\mathrm{mmol} / \mathrm{l})$ & $4.65 \pm 1.12$ & $4.4 \pm 0.97$ & $4.3 \pm 1.06$ & 0.078 & 0.324 & 0.038 \\
\hline HDL-cholesterol $(\mathrm{mmol} / \mathrm{l})$ & $1.15 \pm 0.28$ & $1.2 \pm 0.28$ & $1.22 \pm 0.29$ & 0.218 & 0.649 & 0.235 \\
\hline Triglycerides (mmol/l) & $1.92 \pm 0.99$ & $1.63 \pm 0.57$ & $1.69 \pm 0.75$ & 0.060 & 0.541 & 0.026 \\
\hline LDL-cholesterol $(\mathrm{mmol} / \mathrm{l})$ & $2.61 \pm 0.93$ & $2.45 \pm 0.85$ & $2.31 \pm 0.92$ & 0.252 & 0.173 & 0.067 \\
\hline VAI & $3.04 \pm 1.87$ & $2.38 \pm 1.31$ & $2.39 \pm 1.31$ & 0.020 & 0.984 & 0.013 \\
\hline GOT (U/l) & $20.7 \pm 9.41$ & $21.4 \pm 9.88$ & $21.1 \pm 10.8$ & 0.692 & 0.799 & 0.969 \\
\hline GPT (U/l) & $26.8 \pm 13.9$ & $18.5 \pm 6.94$ & $17.2 \pm 8.15$ & $<0.001$ & 0.231 & $<0.001$ \\
\hline LAP index & $86.1 \pm 52.4$ & $71.1 \pm 39.1$ & $72.9 \pm 45.1$ & 0.028 & 0.707 & 0.024 \\
\hline Tyg index & $9.57 \pm 0.62$ & $9.05 \pm 0.48$ & $9.05 \pm 0.58$ & $<0.001$ & 0.974 & $<0.001$ \\
\hline TG/HDL-C ratio & $4.12 \pm 2.54$ & $3.14 \pm 1.45$ & $3.23 \pm 1.79$ & 0.020 & 0.719 & 0.016 \\
\hline
\end{tabular}

GPT glutamate pyruvate transaminase, GOT glutamate oxaloacetate transaminase, $V A I$ Visceral Adiposity Index, $L A P$ lipid accumulation product, $T y g$ product of triglycerides and glucose, $T G / H D L-C$ triglycerides to HDL-cholesterol ratio ${ }^{*}$ Comparison between baseline and 6 months of treatment ${ }^{* *}$ Comparison between 6 and 12 months of treatment ${ }^{* * *}$ Comparison between baseline and 12 months of treatment

Tyg index, TG/HDL-C ratio and VAI after 6 months of treatment with the persistence of these effects at 12 months of follow-up. These results confirm previous findings [3] and demonstrate the efficacy of dapagliflozin therapy in terms not only of metabolic control but also of extraglycaemic cardiovascular benefits.
The VAI is a validated indirect index of cardiometabolic risk and a valuable index of both fat distribution and function. This has been demonstrated by the correlation between magnetic resonance imaging measurement of visceral adipose tissue and VAI, and between VAI and insulin sensitivity, evaluated by the 
Table 3 Clinical, anthropometric and metabolic parameters in diabetic patients before and after triple combined therapy of dapaglifozin, metformin and long-acting insulin

Triple combined treatment (dapaglifozin + metformin + insulin)

\begin{tabular}{lcccccc}
\hline & $\begin{array}{l}\text { Baseline } \\
\text { Mean } \pm \text { SD }\end{array}$ & $\begin{array}{l}\text { 6 months } \\
\text { Mean } \pm \text { SD }\end{array}$ & $\begin{array}{l}\text { 12 months } \\
\text { Mean } \pm \text { SD }\end{array}$ & $p^{*}$ & $p^{* *}$ & $p^{* * *}$ \\
\hline Body mass index $\left(\mathrm{kg} / \mathrm{m}^{2}\right)$ & $33.3 \pm 4.93$ & $32.4 \pm 5.17$ & $32.5 \pm 5.69$ & $<0.001$ & 0.738 & $<0.001$ \\
Waist circumference $(\mathrm{cm})$ & $113.3 \pm 12.6$ & $111.3 \pm 12.2$ & $111 \pm 12.8$ & $<0.001$ & 0.344 & $<0.001$ \\
Systolic blood pressure $(\mathrm{mmHg})$ & $128.7 \pm 9.15$ & $125.1 \pm 8.57$ & $124.4 \pm 7.91$ & 0.015 & 0.556 & 0.001 \\
Diastolic blood pressure $(\mathrm{mmHg})$ & $85.3 \pm 9.66$ & $81.5 \pm 10.5$ & $80.9 \pm 8.01$ & 0.027 & 0.730 & 0.002 \\
Mean fasting glycaemia $(\mathrm{mmol} / \mathrm{l})$ & $12.1 \pm 3.26$ & $8.81 \pm 2.58$ & $9.03 \pm 2.83$ & $<0.001$ & 0.546 & $<0.001$ \\
Mean 2 h post breakfast glycaemia $(\mathrm{mmol} / \mathrm{l})$ & $12.7 \pm 3.34$ & $9.51 \pm 2.25$ & $9.04 \pm 2.83$ & $<0.001$ & 0.510 & $<0.001$ \\
Mean 2 h post-lunch glycaemia $(\mathrm{mmol} / \mathrm{l})$ & $12.5 \pm 2.33$ & $9.79 \pm 2.44$ & $9.58 \pm 2.69$ & $<0.001$ & 0.600 & $<0.001$ \\
Mean 2 h post dinner glycaemia $(\mathrm{mmol} / \mathrm{l})$ & $12.8 \pm 2.96$ & $9.88 \pm 2.06$ & $9.16 \pm 2.54$ & $<0.001$ & 0.052 & $<0.001$ \\
Total insulin requirement $(\mathrm{U} / \mathrm{kg})$ & $0.52 \pm 0.36$ & $0.53 \pm 0.35$ & $0.56 \pm 0.44$ & 0.724 & 0.830 & 0.690 \\
HbAlc (\%) & $9.48 \pm 1.23$ & $7.96 \pm 1.14$ & $7.95 \pm 1.11$ & $<0.001$ & 0.987 & $<0.001$ \\
Total cholesterol (mmol/l) & $4.46 \pm 1.23$ & $4.43 \pm 1.07$ & $4.36 \pm 1.07$ & 0.822 & 0.555 & 0.694 \\
HDL-cholesterol $(\mathrm{mmol} / \mathrm{l})$ & $1.16 \pm 0.43$ & $1.21 \pm 0.24$ & $1.22 \pm 0.23$ & 0.310 & 0.575 & 0.469 \\
Triglycerides (mmol/l) & $1.77 \pm 0.99$ & $1.65 \pm 0.71$ & $1.69 \pm 0.77$ & 0.257 & 0.194 & 0.968 \\
LDL-cholesterol (mmol/l) & $2.44 \pm 1.04$ & $2.48 \pm 1$ & $2.35 \pm 0.95$ & 0.743 & 0.238 & 0.469 \\
VAI & $2.95 \pm 2.09$ & $2.51 \pm 1.44$ & $2.64 \pm 1.63$ & 0.040 & 0.259 & 0.145 \\
GOT (U/l) & $23.6 \pm 13.2$ & $23.3 \pm 15.3$ & $23.6 \pm 12.1$ & 0.879 & 0.875 & 0.844 \\
GPT (U/l) & $30.8 \pm 16.4$ & $20.6 \pm 12.2$ & $19.1 \pm 8.45$ & $<0.001$ & 0.164 & $<0.001$ \\
LAP index & $95.4 \pm 63.8$ & $84.3 \pm 46.8$ & $89.6 \pm 47.6$ & 0.047 & 0.251 & 0.161 \\
Tyg index & $9.57 \pm 0.63$ & $9.25 \pm 0.56$ & $9.32 \pm 0.58$ & $<0.001$ & 0.232 & 0.003 \\
TG/HDL-c ratio & $3.97 \pm 2.81$ & $3.32 \pm 1.76$ & $3.49 \pm 1.88$ & 0.048 & 0.393 & 0.116 \\
\hline
\end{tabular}

GPT glutamate pyruvate transaminase, GOT glutamate oxaloacetate transaminase, $V A I$ Visceral Adiposity Index, $L A P$ lipid accumulation product, $T y g$ product of triglycerides and glucose, $T G / H D L-C$ triglycerides to HDL-cholesterol ratio ${ }^{*}$ Comparison between baseline and 6 months of treatment

${ }^{* *}$ Comparison between 6 and 12 months of treatment

${ }^{* * *}$ Comparison between baseline and 12 months of treatment

hyperinsulinaemic-euglycaemic clamp [15]. Notably, VAI showed an association with the M value that was not detected by WC or BMI alone $[15,16]$. Furthermore, a strong independent association between VAI and both cardiovascular and cerebrovascular events [16, 17] has been reported. In addition, VAI has been widely used in many population studies showing better predictive power for incipient diabetes than its individual components (WC, BMI, TG and HDL) and a correlation with biochemical markers of systemic inflammation linked to adipose tissue dysfunction in patients with T2D $[24,25]$. The LAP index has been proposed and demonstrated as a marker of central obesity and insulin resistance and predictive factor of 

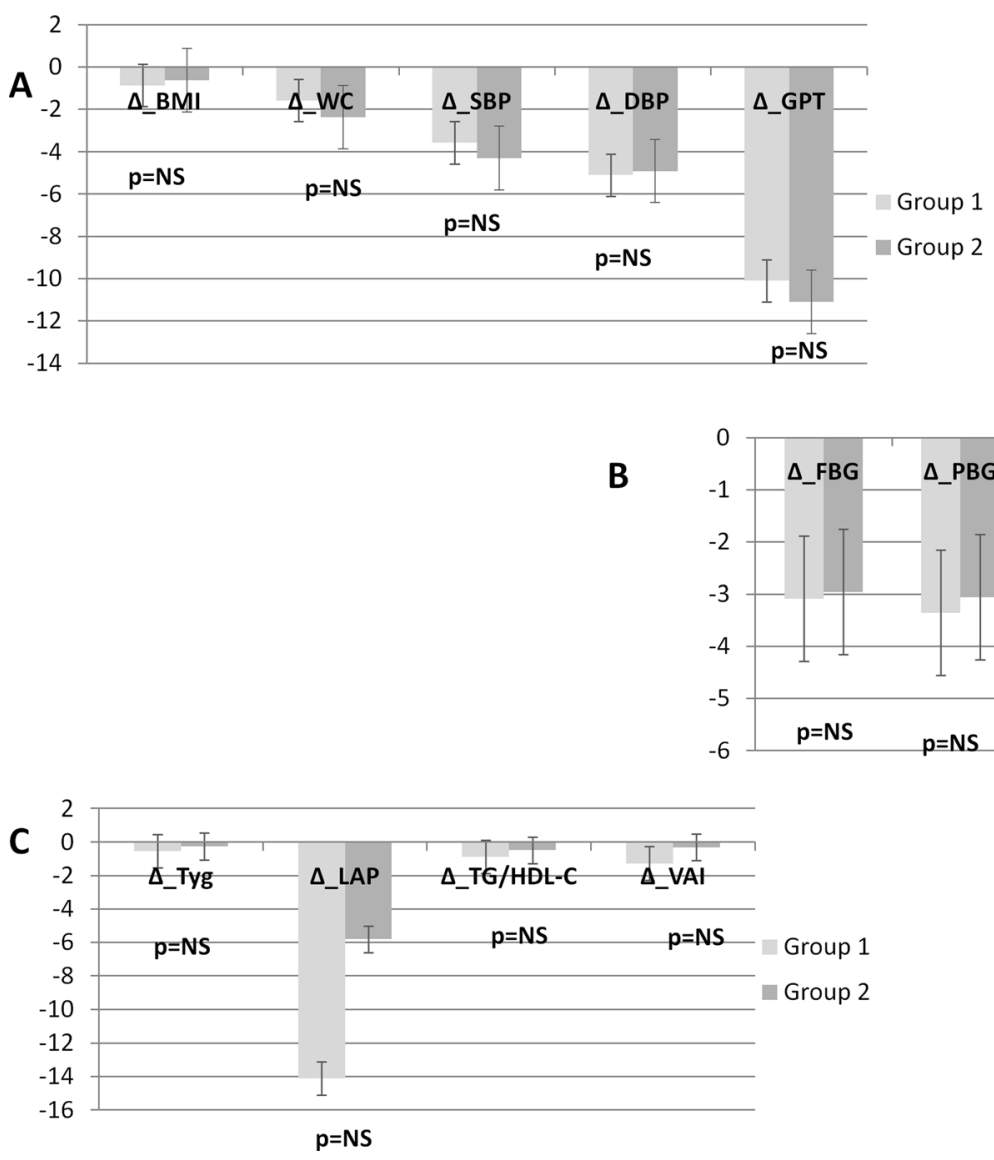

Fig. 1 Comparison of the change $(\Delta)$ from 12 months to baseline between patients on dual and triple combined treatment (groups 1 and 2) for those parameters which were statistically significant at the Student's $t$-test analysis. a Comparison of $\Delta_{-}$BMI, $\Delta_{-}$WC, $\Delta_{-}$SBP, $\Delta_{-}$DBP, $\Delta \_$GPT. b Comparison of $\Delta_{-}$FBG, $\Delta_{-}$PBG, $\Delta_{-}$PLG, $\Delta_{-}$PDG, $\Delta_{-}$HbAlc. c Comparison of $\Delta_{-}$VAI, $\Delta_{-}$LAP, $\Delta_{-}$Tyg, $\Delta_{-}$TG/HDL-C. $B M I$ body mass index, $W C$ waist

metabolic syndrome and cardiovascular disease $[26,27]$. It was also used to discriminate prediabetes and diabetes and was shown to strongly correlate with HOMA-IR [28]. The Tyg index was modelled by Simental-Mendia et al. [29] and validated as a marker of insulin resistance and to discriminate diabetes status $[28,30]$. The TG/HDL-C ratio is a predictor of insulin resistance and cardiometabolic risk and has been proposed as an atherogenic marker [19].

Dapagliflozin improves glucose control and induces weight loss in patients with T2D [7]. Large clinical trials have recently shown that circumference, $S B P$ systolic blood pressure, $D B P$ diastolic blood pressure, $F B G$ fasting blood glycaemia, $P B G$ postbreakfast glycaemia, $P L G$ post-lunch glycaemia, $P D G$ postdinner glycaemia, $V A I$ Visceral Adiposity Index, $L A P$ lipid accumulation product, $T y g$ product of triglycerides and glucose, $T G / H D L-C$ triglycerides to HDL-cholesterol ratio

SGLT2i reduce major adverse cardiovascular events mainly in patients with established atherosclerotic cardiovascular disease. Remarkably, the DAPA-HF (Dapagliflozin and Prevention of Adverse Outcomes in Heart Failure) trial found that dapagliflozin was superior to placebo at preventing cardiovascular deaths and heart failure events [25]. Several studies have reported a significant improvement in epicardial adipose tissue, a parameter reflecting visceral adiposity [6], inflammation markers [7] and hepatic fibrosis [31]. 
A recent randomized controlled trial on 32 patients with T2D showed a decrease in visceral adipose tissue volume measured by magnetic resonance imaging [32]. However, no effects on tissue insulin sensitivity were observed.

In the current study, an interesting positive impact of dapaglifozin on adipose tissue distribution and function indirectly expressed by VAI was found. In agreement with our findings, Neeland et al. reported a significant reduction in VAI in patients with T2D treated with empagliflozin versus placebo, although the follow-up period was short [33]. Similar effects were also found in patients treated with glucagon-like peptide-1 receptor agonists [34, 35]. In the current study, we observed a similar efficacy of dapagliflozin when added to metformin alone or metformin combined with insulin regarding the changes in VAI, suggesting an effect of the drug independent from the concomitant medications. Although, the main mechanism of action of dapaglifozin is the excretion of urinary glucose, dapaglifozin also exerts a cardio-nephroprotective action, whose mechanisms remain elusive. These different pleiotropic extraglycaemic effects have a positive impact on visceral adipose dysfunction and contribute to a decreased risk of cardiovascular events, heart failure and diabetic kidney disease progression [36]. Except for reduced body weight, an alternative hypothesis explaining loss of liver fat is the metabolic substrate shift from glucose to fatty acids and possibly increased fatty acid oxidation in the liver as previously suggested [37, 38]. Interestingly, in the current study dapaglifozin addition provided a decrease in other validated surrogate markers of insulin resistance: the LAP index, Tyg index and TG/HDL-C ratio. The positive effects of dapaglifozin on insulin resistance have been evaluated in both humans by meal test and euglycaemic hyperinsulinemic clamp [39] and transgenic rat models [40].

The main limitation of our study is the nonevaluation of adiposity by imaging techniques and neither inflammatory biomarkers nor adipokines. Another limitation is the absence of a meaningful control group made up of non-diabetic subjects or patients with T2D not treated with dapaglifozin. The strength of the study is the evaluation of the main important validated surrogates of adiposity and insulin resistance, the VAI, LAP index, Tyg index and TG/HDL-C ratio in patients treated with dapaglizofin.

The results of the current study must be considered as preliminary. Further larger prospective studies need to be performed to confirm these results.

\section{CONCLUSION}

Our study confirms the efficacy of dapagliflozin in achieving stable metabolic and glycaemic control and contributing to the improvement in other extraglycaemic targets (BMI, WC, SBP, DBP and TG levels) in a real-life single-centre cohort of patients with T2D. In addition, changes in body composition induced by dapaglifozin improve surrogate indexes of adiposity and insulin resistance. However, further prospective studies with a high number of patients with T2D and a longer period of observation are required to confirm these preliminary data.

\section{ACKNOWLEDGEMENTS}

We thank the participants of the study.

Funding. No funding or sponsorship was received for this study or publication of this article. Editorial support was provided by Edra S.p.A, and the rapid service fee was unconditionally funded by AstraZeneca.

Disclosures. Stefano Radellini, Enrica Vigneri, Felicia Pantò, Valentina Guarnotta and Carla Giordano declare that they have no conflict of interest.

Compliance with Ethics Guidelines. Approval was obtained from the Ethics Committee of the Policlinico Paolo Giaccone Hospital, University of Palermo. All procedures were in accordance with the ethical standards of the local committee on human experimentation (institutional and national) and with the Declaration of Helsinki (1964) and its later 
amendments. At the time of the first visit in our Out-Patients' Clinic, all patients provided informed consent to participate in the study and for the publication of the study.

Data Availability. All data generated or analyzed during this study are included in this published article.

Authorship. All named authors meet the International Committee of Medical Journal Editors (ICMJE) criteria for authorship for this article, take responsibility for the integrity of the work as a whole, and have given their approval for this version to be published.

Authors' Contributions. VG, SR: manuscript writing, data analysis and editing; EV, FP: data collection; CG, VG: protocol development and editing; VG, SR, EV, FP and C.G. read and approved the final manuscript for publication.

Open Access. This article is licensed under a Creative Commons Attribution-NonCommercial 4.0 International License, which permits any non-commercial use, sharing, adaptation, distribution and reproduction in any medium or format, as long as you give appropriate credit to the original author(s) and the source, provide a link to the Creative Commons licence, and indicate if changes were made. The images or other third party material in this article are included in the article's Creative Commons licence, unless indicated otherwise in a credit line to the material. If material is not included in the article's Creative Commons licence and your intended use is not permitted by statutory regulation or exceeds the permitted use, you will need to obtain permission directly from the copyright holder. To view a copy of this licence, visit http://creativecommons.org/licenses/bync/4.0/.

\section{REFERENCES}

1. American Diabetes Association. Pharmacologic approaches to glycemic treatment: Standards of Medical Care in Diabetes 2018. Diabetes Care. 2018;41:S73-85.
2. Xourgia E, Papazafiropoulou A, Melidonis A. Effects of antidiabetic drugs on epicardial fat. World J Diabetes. 2018;9:141-8.

3. Monami M, Nardini C, Mannucci E. Efficacy and safety of sodium glucose co-transport- 2 inhibitors in type 2 diabetes: a meta-analysis of randomized clinical trials. Diabetes Obes Metab. 2014;16: 457-66.

4. Okamoto A, Yokokawa H, Sanada H, Naito T. Changes in levels of biomarkers associated with adipocyte function and insulin and glucagon kinetics during treatment with dapagliflozin among obese type 2 diabetes mellitus patients. Drugs RD. 2016;16:255-61.

5. Honda $\mathrm{Y}$, Imajo $\mathrm{K}$, Kato $\mathrm{T}$, Kessoku T, Ogawa $\mathrm{Y}$, Tomeno W, Kato S, Mawatari H, Fujita K, Yoneda M, Saito S, Nakajima A. The selective SGLT2 inhibitor ipragliflozin has therapeutic effect on nonalcoholic steatohepatitis in mice. PLoS ONE. 2016;11: e0146337.

6. Sato T, Aizawa Y, Yuasa S, Kishi S, Fuse K, Fujita S, Ikeda Y, Kitazawa H, Takahashi M, Sato M, Okabe $M$. The effect of dapagliflozin treatment on epicardial adipose tissue volume. Cardiovasc Diabetol. 2018;17:6.

7. Díaz-Rodríguez E, Agra RM, Fernández ÁL, Adrio B, García-Caballero T, González-Juanatey JR, Eiras S. Effects of dapagliflozin on human epicardial adipose tissue: modulation of insulin resistance, inflammatory chemokine production, and differentiation ability. Cardiovasc Res. 2018;114:336-46.

8. Bolinder J, Ljunggren Ö, Kullberg J, Johansson L, Wilding J, Langkilde AM, Sugg J, Parikh S. Effects of dapagliflozin on body weight, total fat mass, and regional adipose tissue distribution in patients with type 2 diabetes mellitus with inadequate glycemic control on metformin. J Clin Endocrinol Metab. 2012;97:1020-31.

9. Radholm K, Zhou Z, Clemens K, Neal B, Woodward $M$. Effects of sodium-glucose co-transporter-2 inhibitors in type 2 diabetes in women versus men. Diabetes Obes Metab. 2020;22:263-6.

10. Neal B, Perkovic V, Mahaffey KW, de Zeeuw D, Fulcher G, Erondu N, Shaw W, Law G, Desai M, Matthews DR, CANVAS Program Collaborative Group. Canagliflozin and cardiovascular and renal events in type 2 diabetes. N Engl J Med. 2017;377: 644-57.

11. Bin Hussain AK, Abdelgadir E, Rashid F, Al Haj A, Thadani P, Bashier AMK. Should metformin still be the first-line of treatment in type 2 diabetes mellitus? A comprehensive review and suggested algorithm. Diabetes Metab Syndr. 2019;13:1935-42. 
12. Heerspink HJL, Stefánsson BV, Correa-Rotter $\mathrm{R}$, Chertow GM, Greene T, Hou FF, Mann JFE, McMurray JJV, Lindberg M, Rossing P, Sjöström CD, Toto RD, Langkilde AM, Wheeler DC, DAPA-CKD Trial Committees and Investigators. Dapagliflozin in patients with chronic kidney disease. N Engl J Med. 2020;383:1436-46.

13. Wiviott SD, Raz I, Bonaca MP, Mosenzon O, Kato ET, Cahn A, Silverman MG, Zelniker TA, Kuder JF, Murphy SA, Bhatt DL, Leiter LA, McGuire DK, Wilding JPH, Ruff CT, Gause-Nilsson IAM, Fredriksson M, Johansson PA, Langkilde AM, Sabatine MS, DECLARE-TIMI 58 Investigators. Dapagliflozin and cardiovascular outcomes in type 2 diabetes. N Engl J Med. 2019;380:347-57.

14. Amato MC, Giordano C, Galia M, Criscimanna A, Vitabile S, Midiri M, Galluzzo A, AlkaMeSy Study Group. Visceral Adiposity Index: a reliable indicator of visceral fat function associated with cardiometabolic risk. Diabetes Care. 2010;33:920-2.

15. Amato MC, Giordano C, Pitrone M, Galluzzo A. Cut-off points of the visceral adiposity index (VAI) identifying a visceral adipose dysfunction associated with cardiometabolic risk in a Caucasian Sicilian population. Lipids Health Dis. 2011;10:183.

16. Amato MC, Pizzolanti G, Torregrossa V, Misiano G, Milano S, Giordano C. Visceral Adiposity Index (VAI) is predictive of an altered adipokine profile in patients with type 2 diabetes. PLoS ONE. 2014;9: e91969.

17. Amato MC, Guarnotta V, Giordano C. Body composition assessment for the definition of cardiometabolic risk. J Endocrinol Invest. 2013;36: 537-43.

18. DeFronzo RA, Tobin JD, Andres R. Glucose clamp technique: a method for quantifying insulin secretion and resistance. Am J Physiol. 1979;237: E214-23.

19. Fiorentino TV, Marini MA, Succurro E, Andreozzi F, Sesti G. Relationships of surrogate indexes of insulin resistance with insulin sensitivity assessed by euglycemic hyperinsulinemic clamp and subclinical vascular damage. BMJ Open Diabetes Res Care. 2019; 7:e000911.

20. American Diabetes Association. Microvascular complications and foot care: Standards of Medical Care in Diabetes-2021. Diabetes Care. 2021;44(Suppl 1):S151-67.

21. Kahn HS. The "lipid accumulation product" performs better than the body mass index for recognizing cardiovascular risk: a population-based comparison. BMC Cardiovasc Disord. 2005;5:26.
22. Guerrero-Romero F, Simental-Mendía LE, GonzálezOrtiz M, Martínez-Abundis E, Ramos-Zavala MG, Hernández-González SO, Jacques-Camarena O, Rodríguez-Morán M. The product of triglycerides and glucose, a simple measure of insulin sensitivity. Comparison with the euglycemic-hyperinsulinemic clamp. J Clin Endocrinol Metab. 2010;95:3347-51.

23. Abbasi F, Reaven GM. Comparison of two methods using plasma triglyceride concentration as a surrogate estimate of insulin action in nondiabetic subjects: triglycerides $\times$ glucose versus triglyceride/ high-density lipoprotein cholesterol. Metabolism. 2011;60:1673-6.

24. Alkhalaqi A, Al-Naimi F, Qassmi R, Shi Z, Ganji V, Salih R, Bawadi H. Visceral adiposity index is a better predictor of type 2 diabetes than body mass index in Qatari population. Medicine (Baltimore). 2020;99:e21327.

25. McMurray JJV, Solomon SD, Inzucchi SE, Køber L, Kosiborod MN, Martinez FA, Ponikowski P, Sabatine MS, Anand IS, Bělohlávek J, Böhm M, Chiang CE, Chopra VK, de Boer RA, Desai AS, Diez M, Drozdz J, Dukát A, Ge J, Howlett JG, Katova T, Kitakaze M, Ljungman CEA, Merkely B, Nicolau JC, O'Meara E, Petrie MC, Vinh PN, Schou M, Tereshchenko S, Verma S, Held C, DeMets DL, Docherty KF, Jhund PS, Bengtsson $\mathrm{O}$, Sjöstrand $\mathrm{M}$, Langkilde AM, DAPA-HF Trial Committees and Investigators. Dapagliflozin in patients with heart failure and reduced ejection fraction. N Engl J Med. 2019;381:1995-2008.

26. Xia C, Li R, Zhang S, Gong L, Ren W, Wang Z, Li Q. Lipid accumulation product is a powerful index for recognizing insulin resistance in non-diabetic individuals. Eur J Clin Nutr. 2012;66:1035-8.

27. Sambataro M, Perseghin G, Lattuada G, Beltramello G, Luzi L, Pacini G. Lipid accumulation in overweight type 2 diabetic subjects: relationships with insulin sensitivity and adipokines. Acta Diabetol. 2013;50:301-7.

28. Ahn N, Baumeister SE, Amann U, Rathmann W, Peters A, Huth C, Thorand B, Meisinger C. Visceral Adiposity Index (VAI), lipid accumulation product (LAP), and product of triglycerides and glucose (TyG) to discriminate prediabetes and diabetes. Sci Rep. 2019;9:9693.

29. Simental-Mendía LE, Rodríguez-Morán M, Guerrero-Romero $\mathrm{F}$. The product of fasting glucose and triglycerides as surrogate for identifying insulin resistance in apparently healthy subjects. Metab Syndr Relat Disord. 2008;6:299-304.

30. Du T, Yuan G, Zhang M, Zhou X, Sun X, Yu X. Clinical usefulness of lipid ratios, visceral adiposity indicators, and the triglycerides and glucose index 
as risk markers of insulin resistance. Cardiovasc Diabetol. 2014;13:146.

31. Shimizu M, Suzuki K, Kato K, Jojima T, Iijima T, Murohisa T, Iijima M, Takekawa H, Usui I, Hiraishi $\mathrm{H}$, Aso Y. Evaluation of the effects of dapagliflozin, a sodium-glucose co-transporter-2 inhibitor, on hepatic steatosis and fibrosis using transient elastography in patients with type 2 diabetes and nonalcoholic fatty liver disease. Diabetes Obes Metab. 2019;21:285-92.

32. Latva-Rasku A, Honka MJ, Kullberg J, Mononen N, Lehtimäki T, Saltevo J, Kirjavainen AK, Saunavaara V, Iozzo P, Johansson L, Oscarsson J, Hannukainen JC, Nuutila P. The SGLT2 inhibitor dapagliflozin reduces liver fat but does not affect tissue insulin sensitivity: a randomized, double-blind, placebocontrolled study with 8-week treatment in type 2 diabetes patients. Diabetes Care. 2019;42:931-7.

33. Neeland IJ, McGuire DK, Chilton R, Crowe S, Lund SS, Woerle HJ, Broedl UC, Johansen OE. Empagliflozin reduces body weight and indices of adipose distribution in patients with type 2 diabetes mellitus. Diab Vasc Dis Res. 2016;13:119-26.

34. Ciresi A, Vigneri E, Radellini S, Pantò F, Giordano C. Liraglutide improves cardiovascular risk as an addon to metformin and not to insulin secretagogues in type 2 diabetic patients: a real-life 48 -month retrospective study. Diabetes Ther. 2018;9:1413.

35. Russo GT, Labate AM, Giandalia A, Romeo EL, Villari P, Alibrandi A, Perdichizzi G, Cucinotta D.
Twelve-month treatment with liraglutide ameliorates Visceral Adiposity Index and common cardiovascular risk factors in type 2 diabetes outpatients. J Endocrinol Invest. 2015;38:81-9.

36. Scheen AJ. Sodium-glucose cotransporter type 2 inhibitors for the treatment of type 2 diabetes mellitus. Nat Rev Endocrinol. 2020;16:556-77.

37. Ferrannini E, Muscelli E, Frascerra S, Baldi S, Mari A, Heise T, Broedl UC, Woerle HJ. Metabolic response to sodium-glucose cotransporter 2 inhibition in type 2 diabetic patients. J Clin Invest. 2014;124: 499-508.

38. Daniele G, Xiong J, Solis-Herrera C, Merovci A, Eldor R, Tripathy D, DeFronzo RA, Norton L, AbdulGhani M. Dapagliflozin enhances fat oxidation and ketone production in patients with type 2 diabetes. Diabetes Care. 2016;39:2036-41.

39. Merovci A, Abdul-Ghani M, Mari A, Solis-Herrera C, Xiong J, Daniele G, Tripathy D, DeFronzo RA. Dapagliflozin improves muscle insulin sensitivity but enhances endogenous glucose production. J Clin Invest. 2014;124:509-14.

40. Joannides CN, Mangiafico SP, Waters MF, Lamont BJ, Andrikopoulos S. Dapagliflozin improves insulin resistance and glucose intolerance in a novel transgenic rat model of chronic glucose overproduction and glucose toxicity. Diabetes Obes Metab. 2017;19:1135-46. 